\title{
Childbirth and Infancy in Greek and Roman Antiquity
}

\author{
Véronique Dasen
}

\section{Introduction}

Long believed to be a transitional time that left no trace, birth and early childhood have recently emerged as a new field of research. Interdisciplinary approaches have demonstrated that coming into life has a complex and rich history of its own in classical antiquity, involving important issues relating to the history of medicine, religion, family and gender studies. New impulses also came from the results obtained for other periods and societies, allowing useful transfers of questioning on various topics, from the function of babies' "molding" to fosterage relations. In this chapter we will analyze a series of key themes in a comparative way, highlighting similarities and specificities, in search of the many-folded perception of young children in Greek and Roman antiquity. The extent of comparison is uneven because of the lacunary and changing nature of evidence in each culture. Textual sources relating to that first stage of life are limited: infants were mainly in the hands of women, who left almost no direct written evidence. We will also concentrate on freeborn and mostly elite children, as nothing or very little is known about lower-class ones and those born in slavery. Traces of children in material culture (feeding bottles, amulets, toys, etc.) partly compensate the paucity of literary sources, but the interpretation of objects from various contexts (funerary, votive, domestic, etc.) is often still a matter of debate.

\section{Infancy: Definitions}

Growing up in antiquity was not perceived as a continuum: the process was composed of stages associated with the gradual integration into the community, often marked by 
ritual acts. In times of high infant mortality, these stages represented steps for hope of survival and increasing parental bonding. Our notion of "early childhood" or "infancy" could correspond to the stage ending around two or three years which appears within the traditional Greek and Roman scheme dividing human life into hebdomads. After teething, which occurs around six or seven months, a second important transition takes place at two or three when the infant is definitely weaned. The child is no more treated by the nurse's milk, but independently. He or she can talk. It is also a time of increased physical activity; the bones are believed to have hardened enough, and children can freely walk and play outside. The turning point is social and religious too; in places like Classical Athens, the three-year old was involved for the first time in the religious life of the community.

Greek and Latin vocabulary, however, do not reflect this structure. Apart from the generic pais in Greek and puer in Latin, more specific words exist (brephos, nepios, teknon, paidion, paidarion), but they do not clearly delineate stages in the child's development (Golden (1990) 12-22). Their use varies mainly according to literary genre; they express types of bondage rather than age groups, such as teknon (after tikt $\hat{o}$, "I give birth"), that describes not only babies but also children of all ages with a strong emotional connotation.

In Latin literature, infans and infantia appear by the end of the first century BCE, along with new terms, such as bimus or bimulus, denoting the two-year-old child (for example, CIL 6.5861, 6.6031, 6.16739). M. Manson ((1978), (1983)) thought that linguistic changes could mirror social ones, and that the formula puer bimulus witnessed a new interest for infants under Augustus' reign. The question is much debated. The changing nature of evidence can mislead historians. "Changes in genre are mistaken for changes in mentality," as A. Cohen states it (in Cohen and Rutter (2007) 8; Golden (1992)). In all periods, other types of evidence, such as iconography or funerary rites, also reveal awareness of infants, as well as a continuing, but shifting perception of stages within childhood, warning us about oversimplifying historical changes.

\section{Medical Views}

One could assume that the absence of ancient medical treatise addressing specifically infants' care, equivalent to modern pediatrics, implies a lack of interest because of the high infant mortality. For R. Etienne (1973), babies, too fragile, had little social value, and were not worth medical discussion; their care was relegated to women the midwife, the nurse, or the mother - and the intervention of a physician would be exceptional. This view must be corrected. Discussions of infants may not be comprehensive, but they are recurrent and demonstrate consciousness of the characteristics of children who form a distinct epidemiological group. Recent researches, mainly based on authors of the Roman imperial period, under the impulse of Soranus' rediscovery, have also shown that the few therapeutic treatments applied to infants must be contrasted with numerous prescriptions about hygiene and diet aiming at promoting survival and a healthy growth. 


\subsection{Infants' Physiology}

From Hippocrates to Late Antiquity, babies and toddlers are defined as a category of beings with a special morphology and physiology. These characteristics are on the whole negative. Newborn babies are generally described as imperfect, weak and ugly. Imperfect because humans are born incomplete: "They are born in a more imperfect condition than any other perfected animal," says Aristotle (Generation of Animals 5.1.779a24). Ugly, because they have a red face, little hair (On Colours 6.797b24-30) and a poor eyesight, indicated by their pale-blue eyes due to the lack of food which provoked the birthing process (Generation of Animals 5.1.779a-780b). Medical authors are also concerned with the malleability of the babies' body, compared with wax, even in the bones, and recommend swaddling immediately after birth (for example, Galen, On Temperaments 2.2 = Kühn 1.578).

The first week of life represents the first critical stage. Aristotle explains that many children die within the first week, and hence are named only past that period (History of Animals 588a8-10). Becoming human then starts as a long process. For a week, before the loss of its dried umbilical cord, the newborn child "is more like a plant than an animal," says Plutarch (Roman Questions 288C). A mineral metaphor substitutes for the vegetal one in Chronos' myth, who ate his children as soon as they were born and thought a stone to be a swaddled nursling.

During the first 40 days nurslings sleep most of the time and seem to be deprived of sensations, a long-lived belief with important therapeutic consequences that were only corrected in the second half of the twentieth century. Continuous sleep was also regarded as part of a transition state, between living and not living:

The transition from not being to being is effected through the intermediate state, and sleep would appear to be by its nature a state of this sort, being as it were a borderland between living and not living: a person who is asleep would appear to be neither completely nonexistent nor completely existent. (Aristotle, Generation of Animals 5.1.778b28)

When the baby has passed the first 40 critical days, it emerges as the opposite, a fierce, hot-tempered creature, dominated by emotions and sensations. Moister and hotter than adults, the baby is also greedier and angrier. "Of all wild creatures, the child is the most intractable," says Plato (Laws 7.808D). Some authors recommend coddling to prevent infant's crying (Plato, Laws 7.792A), others, less permissive, consider crying as a natural form of exercise (Aristotle, Politics 7.17.1336a).

For Aristotle, infants are defined as a lower category of beings, physically weak, mentally and morally inept, with uncontrolled appetites. Physical disproportions associate them with animals. A heavy upper part explains why children move like quadrupeds, says Aristotle: "That is why infants cannot walk but crawl about, and at the very beginning cannot even crawl, but remain where they are" (Generation of Animals 686b8-11). The predominance of remedies derived from animals to treat children mirrors their similar temperaments and qualities, reflected by their close relations in daily life. This notion of wildness also has social and religious consequences: it explains the protection of Artemis, patron of wild life, and the importance of 
taming rituals, especially for older girls, as in the initiation to Artemis Brauronia (Reeder (1995) 299-314). Disproportions also explain mental incapacities. The heaviness of a large head impairs the impulses of thoughts, and the infant's memory is bad. Children are further associated with inferior categories of human beings, such as old people, physically weaker, with a poorer memory and less hair, with the insane and the drunk, with a similar irritable temperament and a disorderly behavior, with women, irrational, changeable and weak, and even with dwarfs (Dasen (2008b)). These views influenced for many centuries the Western tradition of infants' formative care, physical and mental, from swaddling and massage to feeding.

\subsection{Infants' Diseases}

In ancient medicine, no illness is specific to children, but children have predispositions to specific illnesses that can rapidly become fatal. Harmless disorders, like aphthous ulcers, are innocuous for adults, but, when the painful canker sores invade the mouth, the uvula, and the throat, they hamper proper feeding and can be lethal for sucklings who cannot be easily treated (Celsus, On Medicine 6.11.3).

Medical writers mention two critical periods during infancy. The Hippocratic Aphorisms 3.24-25 (fourth century BCE) distinguish first affections of little and newborn children (paidia), from birth to seven months: aphthae, vomiting, coughs, insomnia, frights, inflammation of the navel, discharges from the ears. The second dangerous stage occurs at seven months, when teething begins: ulceration of the gums, fevers, spasms, and diarrheas, especially when the canine teeth appear (Bertier (1990)). Celsus and other authors of the Roman period repeat these principles (for example, Celsus, On Medicine 2.1.18). A Hippocratic treatise On Dentition reflects the importance of that stage, also an object of great attention in folk medicine, as teeth can "kill": any secondary disorder, such as fever or gum ulceration, could quickly degenerate with dramatic consequences (cf. the French and German expressions mourir des dents, an den Zabnen sterben).

Beside teething, often associated with digestive troubles, diarrheas were feared: "In cases of diarrhea, danger of death is at hand; this disease carries off mostly children up to the age of ten; other ages bear it more easily," explains Celsus (On Medicine 2.8.30), but without linking his observations with malnutrition or poor hygiene.

Until weaning is complete, most diseases, such as skin abscesses, ulcerations and even vesicle stones, were attributed to a defective nurse's milk disturbing the humoral balance: "Children get stones also from the milk, if it be unhealthy, too hot, and bilious" (Hippocrates, Air, Waters, Places 9.40). This long-lasting idea contributed to the misunderstanding of infectious eruptive diseases affecting children only once, like measles or smallpox.

Hot and moist, less robust than adults, children must be treated with moderation, as Celsus says (On Medicine 3.7.1B): "Indeed in general children ought not to be treated like adults. Therefore, as in any other sort of disease, we must set to work with more caution in these cases" (cf. Mudry (2004)). Bloodletting, purging, vomiting, and other strong therapeutics must be avoided, whereas surgery, as in the case of stones, is a last resort. The only medicine regularly applied directly to the infant is preparations with honey to calm ulcerations of the mouth. 


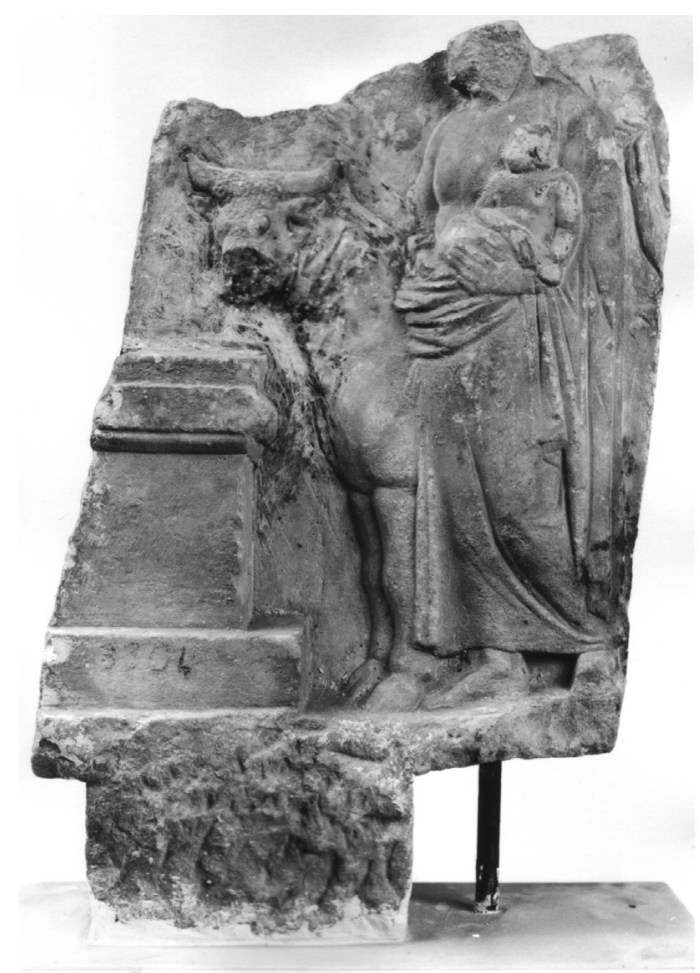

Figure 18.1 Fragmentary marble relief, from the Asclepieion, Piraeus, fourth century BCE. Athens, National Archaeological Museum 3304; courtesy of the Athens Department of the Deutsche Archäologische Institut, Negative No. 1993.342. Photograph by Klaus-Valtin von Eickstedt.

The best way to treat infants until weaning is the nurse's milk that has the property to transmit the qualities of remedies to the child. Constipation, diarrhea, exanthema, aphthous ulcers can be treated through the nurse who must follow the entire treatment, including physical exercises and baths: "For as a general rule, as long as the infant is nursed, we put the wet-nurse on a regimen appropriate to the disease of the child" (Soranus, Gynaecology 24[57]). Even epilepsy could be treated through the nurse's milk (for example, Caelius Aurelianus, On Chronic Diseases 1.4). Was the procedure debated? Some could ask if the remedies would unhappily affect the nurse's health. Soranus (2.24[56]) explains that, appropriately dosed, the product only reaches the baby, since it is more sensitive.

Though filtered by the literary genre, a number of actors appear in these texts, not only women, but also men, the father and male relatives or caretakers, along with the medical doctor (Bradley (2005); Gourevitch (2010)), who do not resign despite the fragility of very young children. The recourse to healing deities was frequent. A baby boy is presented to Asclepius by his father in a procession leading a bull to the sacrificial altar on a relief from the Asclepieion in Piraeus (Figure 18.1) (Lawton (2007) 45 [(Lawton (2007) 45)]). 


\section{Birth}

\subsection{Providing a Legitimate Heir}

The birth of an heir was the principal aim of Greek and Roman marriages which, for strategic reasons, could legally take place as early as 12 years old for girls, especially in wealthy families and in urban contexts, despite the warnings of physicians (see Cox and Dixon, this volume). Many rituals aimed at promoting pregnancy and an easy delivery. Votive figurines of swaddled babies found in Greek as well as in Roman and Gallo-Roman sanctuaries were dedicated on various occasions; some may express the wish to have a child, if possible a boy (Miller Ammerman (2007); de Cazanove (2008)). We do not know how long a young wife could wait before being suspected of infertility, which could be a cause of divorce. Families with one or two children, including at least a boy, seem to have represented an ideal (for example, Hesiod Works and Days 11.376-8; Pliny the Younger, Letters 4.15.3), attained, however, only through several offspring because of the low chances of survival to adulthood.

In classical antiquity, childbirth was usually handled by women who left no or very little written information. Apart from scattered allusions in medical treatises, our main source dates to Roman imperial period: Soranus, a Greek physician from Ephesus, wrote at the beginning of the second century $\mathrm{CE}$ a handbook for the training of midwives which offers an exceptionally detailed description of the procedure and its preparation. The delivery then took place at home, with the help of an experienced woman and female helpers relatives, friends, slaves, or neighbors. Professional midwives, called maia/obstetrix or iatrine/medica, are known in ancient Greece as in Rome; Soranus describes the high level of competence expected from Roman period midwives who should be instructed and own specialized material, such as a birthing chair. The event is seldom realistically depicted. Apart from the famous terracotta plaque of a tomb in Ostia showing the midwife Scribonia Attice at work, the birthing process is usually only alluded to, as in scenes of divine births or on monuments of women who died in childbirth (Neils and Oakley (2003) 185-87).

No men seem to have been present, apart from the physician in case of difficulties, though the distribution of roles between men and women practitioners for normal or abnormal births is debated. The absence of fathers partly explains the fear of being cheated by their wives. The topos of the credulity of husbands manipulated by the duplicity of women goes through the centuries. Aristophanes evokes the strategies of sterile women playing fake pregnancies (Women at the Thesmophoria 502-16) or smuggling a male baby in place of their own girl (Women at the Thesmophoria 564; cf. Juvenal, Satires 6.602-605). In the story of Iphis told by Ovid (Metamorphoses 9.666797 ), the husband orders his wife to abandon the newborn if it is a girl; when the baby girl is born, he believes for years that she delivered a boy, which implies that he never saw his child naked (but cf. Plutarch, Cato the Elder 1.20.4).

Roman legal texts describe how to proceed when paternity is disputed, as in the case of birth after the death of a father. The scene is crowded: the widow gives birth in a room with a single guarded entry, surrounded by female representatives of each family witnessing the labor in order to protect the child's rights and prevent any substitution (D 25.4.1.10, Ulpian; Rawson (2003) 100). 


\subsection{Rites of Passage: Entering Human Life}

How was a new life welcomed in classical antiquity? As in most traditional societies, the newborn enters progressively among the living through steps which fit in the three-phase structure of rites of passage defined by A. van Gennep (1909), consisting of separation, margin and aggregation. Key steps reflect specific cultural representations of the child's body.

A first cycle takes place within the first days, before the official celebration that occurred five or ten days later in Greece (Amphidromia and Dekate), eight or nine days later in Rome (dies lustricus). During that period, the child had no social existence yet, and the father had the right to abandon it with impunity for various reasons, because of her female sex, illegitimacy, or physical abnormalities.

The stages surrounding birth can be reconstructed for Rome with the help of Soranus; his description throws light on the role of the midwife, the main actor in the first day of life.

\subsubsection{The Inspection of the Child}

In the second book of his Gynaecology, we thus read that after delivery the midwife makes a gesture, unfortunately not described, to announce the sex of the newborn. She then puts the child upon the earth and carefully examines its condition. This inspection is decisive because it must determine if the newborn "is worth rearing" (2.5[10]). The child must cry vigorously and be "perfect in all its parts, members and senses: that is ducts, namely of the ears, nose, pharynx, urethra, anus," all must be free from obstruction, says Soranus.

The description details the whole body, from top to toes, with a care reflecting the experience of the newborn's fragility. It also mirrors Roman sensitivity towards physical abnormality, going back to the Republican period. Then a newborn child with severe physical anomalies, such as Siamese twins or a hermaphrodite, was regarded a sign of divine wrath threatening the whole community. It was ritually eliminated, usually thrown to the sea, so as to restore cosmic order (for example, Rosenberger (1998); Brisson (2002) 7-40; Allély (2003), (2004); Cuny-Le Callet (2005)). In the imperial period, major dysfunctions could still cause rejection, as implied by the last sentence of Soranus: "And by conditions contrary to those mentioned, the infant not worth the rearing is recognized." The assertion, however, should not be interpreted literally as we know from other sources that children born with physical defects could be accepted and reared (for example, Pliny, Natural History 7.69, 11.244; Dasen (2006b)). The attention to anomalies is also related to the long-lasting practice of taking omens for the child's future from various bodily signs, such as the untimely presence of teeth (for example, Pliny, Natural History 7.68-89), birthmarks (Suetonius, Augustus 80; Dasen (2009a)) or from the type of delivery, feet first or in the breech position (for example, Pliny, Natural History 7.46). A few texts mention traditions relating to children "born in the caul" (pilleum), enveloped in the amniotic membrane or fragments of it over the head. The caul was kept - or stolen - and sold as a talisman providing good luck (Scriptores Historiae Augustae, Diadumenianus 16.4.2; Belmont (1971)). Multiple 


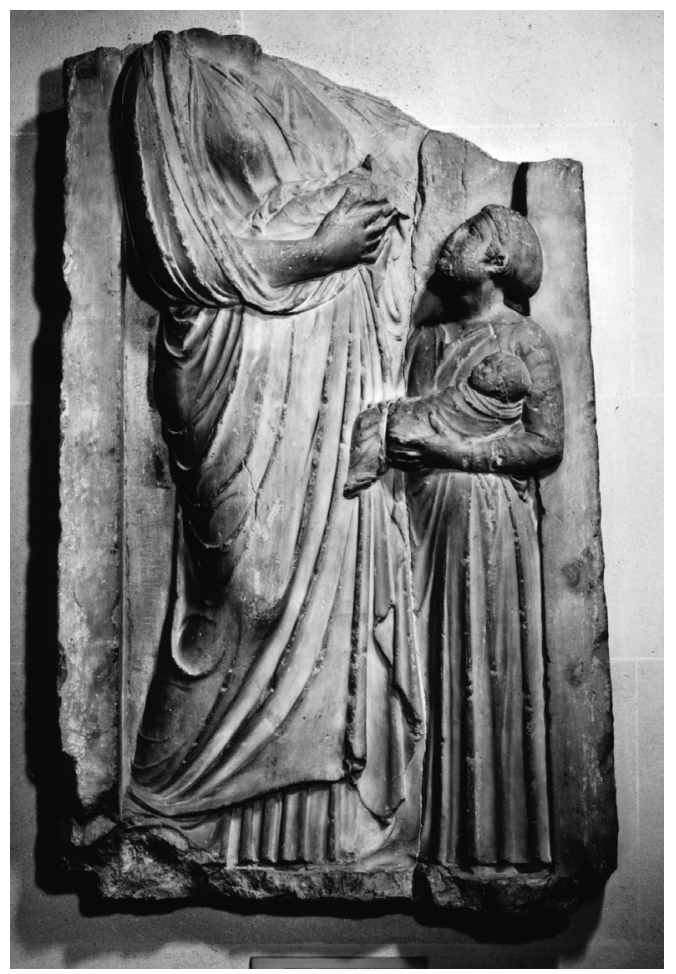

Figure 18.2 Attic marble grave stele, second quarter of the fourth century BCE. Paris, Louvre MA 3113; @ and courtesy of Musée du Louvre/Maurice and Pierre Chuzeville.

births form a special category of offspring, arousing ambivalent reactions, welcomed as a sign of divine favor when they are two (cf. Figure 18.9) or eventually three, portentous, as a disruption of the natural order when three or more are born simultaneously, partly because of the fatal issue of such deliveries (Figure 18.2) (Dasen (2005a), (2005b)).

\subsubsection{Cutting the Umbilical Cord}

This first physical test places the newborn in a liminal stage, between life and death, before the navel cord is cut. Soranus says that the newborn thus had a little rest after the delivery, but other preoccupations may be at work: as long as the navel cord was not cut, the legitimacy of the newborn could be proven, at least in the female line. Lifting the child from the ground was thus a decisive moment, indicating the child's viability. It was performed not by the father, but by the midwife who then severed the umbilical cord. Some avoided iron which would be an ill omen and preferred to use a glass, a potsherd, a reed or bread crust (Soranus, Gynaecology 2.6[11]). The father, if present, ordered proceeding to the first care, thus declaring acceptance of the child, but without any formal ritual, as Köves-Zulauf demonstrated (1990). The lifting-up ceremony is a nineteenth-century creation based on a metaphorical literary expression (tollere or suscipere liberos) (Shaw (2001)). The newborn had a legal existence, as long 


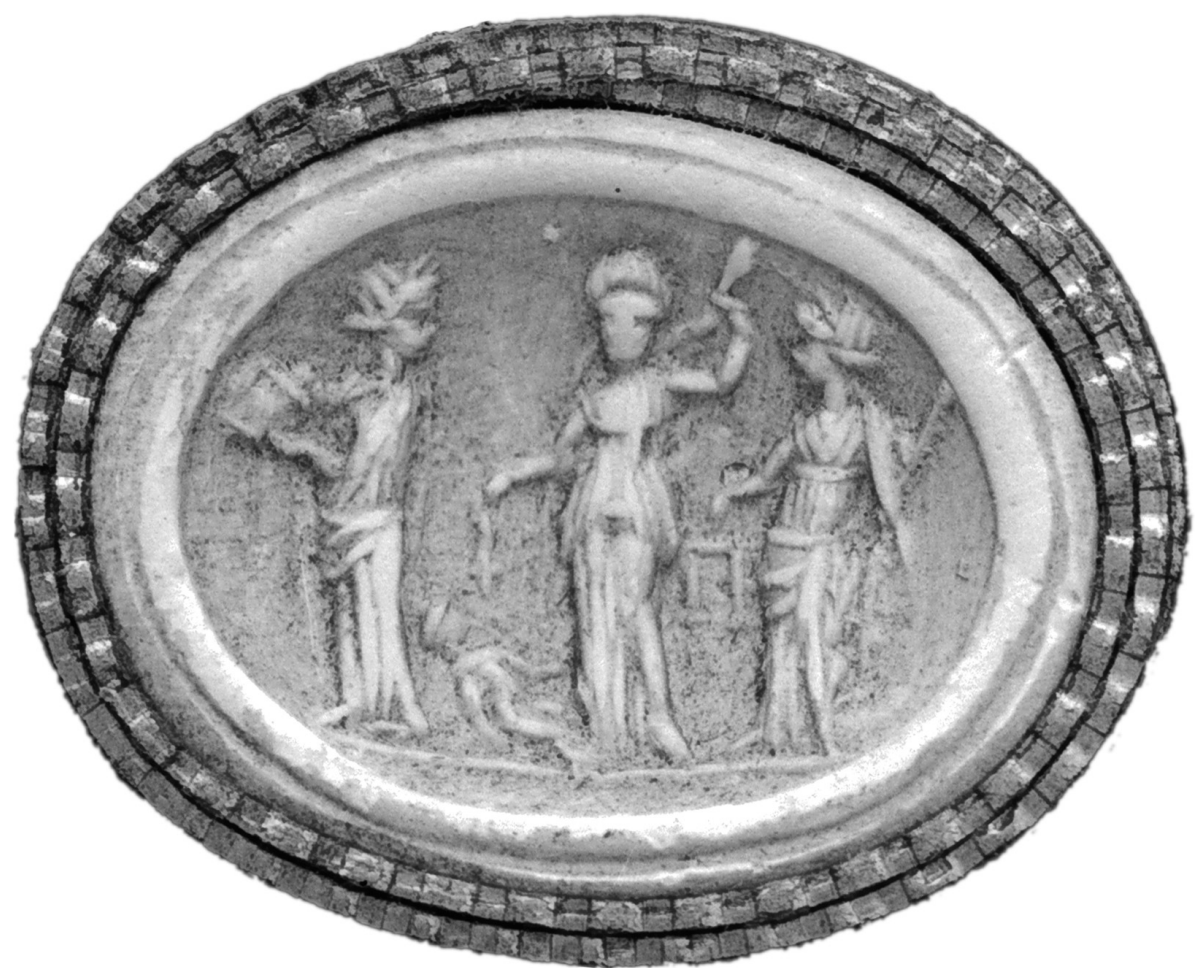

Figure 18.3 Glass paste (cast), Roman period. London, The British Museum 3079; $($ ) and courtesy of the Trustees of the British Museum.

as it was born alive and had cried. The patria potestas was created by the birth itself, whether the father was present or not at the time of delivery, as long as the child was born from a iustum matrimonium between two free citizens. The rights of the child as potential heir even existed before birth; the inheritance rights of the fetus were duly protected (for example, D 28.2.4, Ulpian).

A series of gems of the imperial period seem to refer to the inspection of the physical soundness of the newborn and propose divine models for the midwife (Dasen (2009b) figs 1-3). Three women stand before a child lying or sitting naked on the ground. They hold attributes which identify them with the Parcae (or Moirae or Fatae), who fix the fate of the child (Weiss (1992)). On the London gem, the woman on the left holds a scroll (volumen), that on the right a balance and a torch, both look at the central frontal figure, standing beside the child, who holds a spindle and a distaff (Figure 18.3). The manipulation of spindle and distaff could metaphorically refer to the cutting of the umbilical cord, implying that the midwife is the human doublet of the Parcae or Moirai, like them determining life or death (cf. Ammianus Marcellinus 16.10.19, accusing a midwife of murder) and prospects for the future, providing omina from the birthing position of the child and from other physical signs. 


\subsubsection{Bathing}

Biographical sarcophagi with life-cycle scenes of the second and third centuries CE focus on the next moment, the first bath (Kampen (1981b); Amedick (1991)). Its importance is social first, because caring for the child implies that it has been declared viable, that it is accepted by the parents and that the family starts to be optimistic. Secondly, it introduces the child to earthly life through contact with elements, such as water. Traces of uterine life are washed away: the special coating of the newborn's skin is gently rubbed with fine salt, as Soranus advises (Gynaecology 2.6a[13]); the midwife squeezes out the mucus in the nose, cleanses the mouth and the ears, she also dilates the anus in order to stimulate the excretion of the meconium. With the first bath, a first passage is thus in a sense completed; the child is physically separated from uterine life and he is accepted in the familial group (cf. Suetonius, Claudius 27, disapproving Claudius for exposing his daughter Claudia after allowing procedure to the first care).

In other cultures, reports Soranus (Gynaecology 2.6[12]), the bath represents a selection determining the life or death of the child. Cold water is used by the Germans, the Scythians and "some Greeks," wine, sometimes mixed with brine, or the urine of a child, or myrtle and oak gall. One assumed that the child "not worth the rearing" did not survive.

In life-cycle scenes, the importance of this bath is stressed by the supernatural presence of the Parcae or Moirae. On several sarcophagi, they are depicted fixing the destiny of the newborn on a globe (Figure 18.4). The scenes thus reunite two successive moments, that of the biological birth, when the horoscope is set, and that, symbolical, of the bath, synonymous with the entry into life and the family. Iconography insists on the vigor of the newborn, depicted as an active and older baby, often moving and extending its arms towards its mother. The midwife always presents the child to the mother, no man is present, the environment, human and divine, is entirely female.

Rituals may have enacted this first critical process. Varro (apud Augustine, On the City of God 6.9) describes an ancestral nocturnal rite involving three men representing guardian gods who encircle the house where a successful delivery occurred; their play could metaphorically refer to the first care of the child: severing the umbilical cord (Intercidona and his axe), testing physical soundness (Pilumnus and his pestle), giving the first bath (Deverra and his brooms) (Brind'Amour and Brind'Amour (1971); Köves-Zulauf (1990) 95-219). In Gallo-Roman sculpture, triads of Matres similarly allude to this first rite of passage, associating the swaddled baby with symbolical objects, such as a balance and a volumen (Bauchhenss (1997) 816, B.c, 41.43.44; Deyts (2004); Dasen (2009b) fig. 9).

A successful delivery was finally publicized by placing a laurel wreath at the front door or inscribing the news on the wall of the house (for example, CIL 4.294, $4.3819,4.3890$ ); friends came to the house to congratulate the father and benches were set up in the streets along the house, thus associating passers-by with the festivities (Statius, Silvae. 4.8.37-40; Juvenal, Satires 6.78-80, 85; Aulus Gellius, Attic Nights 12.1). 


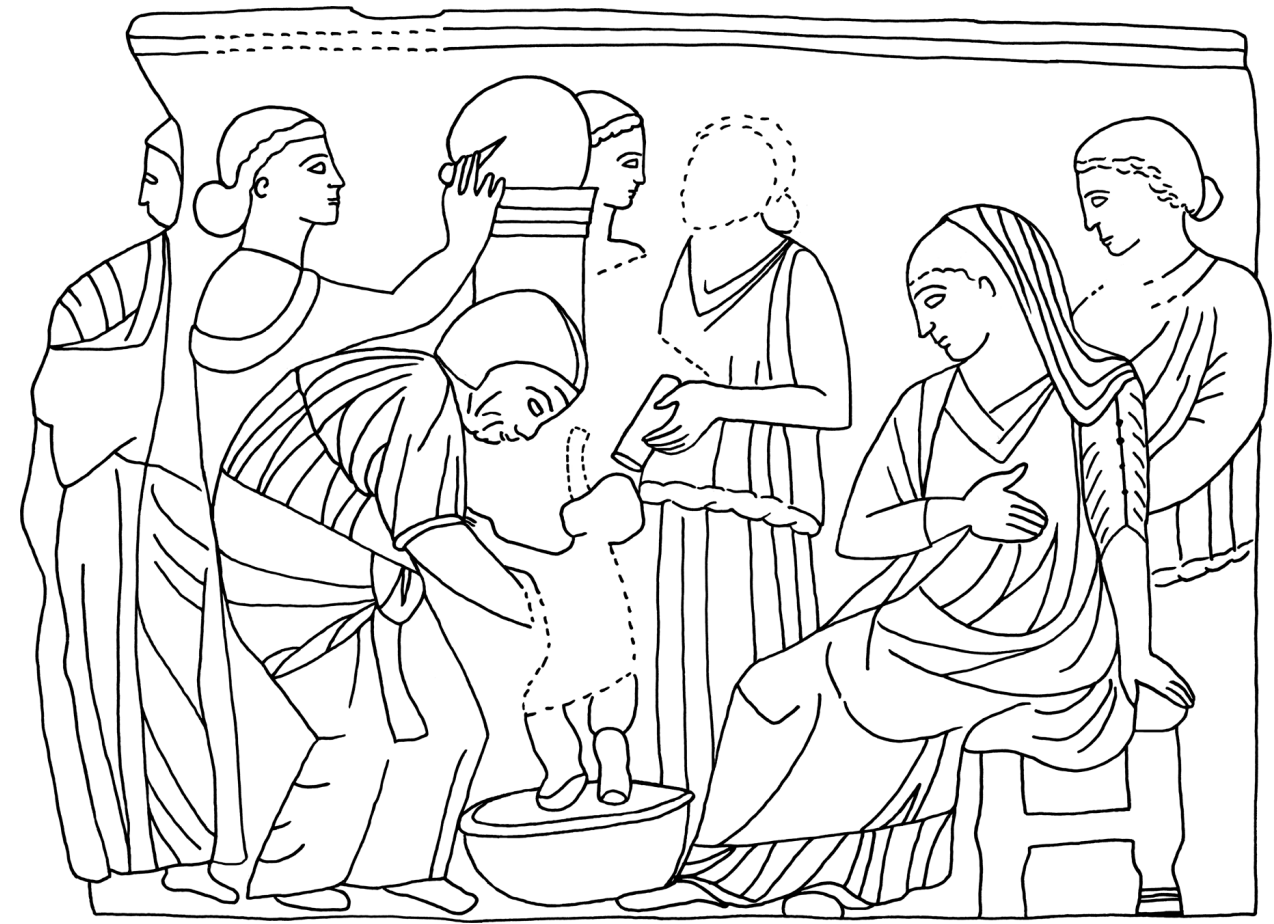

Figure 18.4 Marble sarcophagus, 170-180/200 CE. Agrigento, Museo archeologico Regionale. Drawing by Véronique Dasen.

Were similar rites performed in ancient Greece? Extant sources are very scanty. Most likely the powers of the midwife were also wide-ranging; she knew drugs and incantations to ease the delivery (Plato, Theaetetus $149 \mathrm{c}-\mathrm{d}$ ), and took care of cutting the umbilical cord. The act had certainly a ritual dimension, but no source mentions it. In Sparta, according to Plutarch (Lycurgus 16.1-3; cf. Aristotle, Politics 1336a12-18), the inspection of the newborn was performed by the Council of the Ancients, and the child was bathed with wine in order to test its constitution,

for it is said that epileptic and sickly infants are thrown into convulsions by the strong wine and lose their senses, while the healthy ones are rather tempered by it, like steel, and given a firm habit of body.

In Athens, the midwife may, as in Rome, have immediately proceeded to the physical inspection of the newborn (Plato, Theaetetus 151), or did it occur at the feast of the Amphidromia, which took place about a week later? (Plato, Theaetetus 160e-16la; see below). As in Rome, a happy delivery was announced to the neighborhood: a crown of olive for boys or a tuft of wool for girls was suspended at the door of the house (Hesychius, s.v. stephanon ekpherein; Dasen (2010b)). 


\subsubsection{Shaping the Newborn: Massages and Swaddling}

D. Gourevitch (1994), S.R. Holman (1997) and others drew attention to the socially constructed dimension of formative care which demonstrates a marked concern for infants from birth onwards despite mortality risks. The child is soon subject to the "firming up" of its body, judged so malleable that it can be shaped like wax. Soranus and other authors explain that it is possible to modify this plastic body by massage, modeling "every part so that imperceptibly that which is not yet fully formed is shaped into its natural characteristics" (Gynaecology 2.12[32]). Special emphasis is put on the limbs and mobility, pursuing the squeezing away of viscous material from uterine life which remained in the joints, as Soranus explains:

Furthermore, she should bend back the limbs toward the spine, moving the tip of the right foot towards the tip of the left hand and the left towards the right. For thus the sinews of the joints are made supple, each [of which] becomes more mobile by the various rotations, and if something viscous has penetrated into the joints while the organism was formed, it is squeezed out. (Gynaecology 2.12[32])

Similar ideas are found in other cultures, where massages are thought to make joints and legs supple (Morel and Rollet (2000) 203-208).

Swaddling completes this work. It aimed primarily at preventing distortions in the limbs (Plutarch, On the Education of Children 3D), but symbolically it also contributed to transforming a small shriveled animal into a human, helping it grow as straight as possible. The idea belongs to the longue durée: "Some people believe that children would walk on all fours if they were not swaddled," says N. Brouzet in his Essai sur l'éducation médicinale des enfans (1754).

Roman swaddling made not only human, but also male and female. The type of swaddling differed according to the sex: "In females, one should bind the parts at the breast more tightly, yet keeping the region of the loins loose, for in women this form is more becoming," says Soranus (Gynaecology 2.15[84]). The practice is not without danger. Galen draws attention to ignorant midwives or nurses who deform the child with irregular swaddling that compress the thorax too strongly and unevenly ( $O n$ the Causes of Illness $7=$ Kühn 7.28-29). For Soranus, swaddling may stop after 40 or 60 days, depending on the child's constitution, but one should liberate the right hand first, in order to avoid left-handedness $(2.15[42])$.

Were Greek massage and swaddling practices similar to Roman ones? Theoretical views seem to be similar. Massage is present in the Hippocratic treatise On Regimen 1.19: "Curriers stretch, rub, comb, and wash. Children are tended the same way." Plato, in his $\operatorname{Laws}(7.789 \mathrm{e})$, also compares the embryo and the newborn with wax, and recommends swaddling for two years, adding that the nurse should carry children until the age of three in order to avoid distortions in the legs "by overpressure." Swaddling bands, spargana, seem to cover similarly babies from neck to toes, but iconography suggests variations in time and places, with alternative binding methods. Swaddling material, especially rings for swaddling bands, are now identified in children's tombs, and a systematic collection may throw light on the practice and its variants (Gourevitch 
et al. (2003) Nos 91-94; in Greece, see possibly Prohászka (1995) pls 36B, 36F). Elongating babies' heads is mentioned among the Makrokephaloi (Hippocrates, Airs, Waters, Places 14), but not recommended in Greece, nor Rome (Soranus, Gynaecology $2.12[33])$.

\subsubsection{First Food and Breastfeeding}

The baby is very slowly introduced to human food. "Its whole body is full of maternal food which it ought to digest first," says Soranus (Gynaecology 2.7[17]). One or two days' diet is commonly prescribed. The newborn just gets honey boiled in water, a special food with heavenly connotations. Elaborated from dew, fallen from the sky, honey should keep away evil and diseases, as well as provide divine inspiration (Borgeaud (2004)). This diet belongs, like swaddling, to the longue durée: it was still in use in Europe at the beginning of the twentieth century (Lett and Morel (2006)). After the first days' diet, the newborn gets maternal or a nurse's milk. Animal milk is not recommended, except goat's milk.

\section{Official Entry into the Family/Second, Social, Birth (Amphidromia, Dekate, Dies Lustricus)}

\subsection{Amphidromia, Dekate}

Sources on the first ceremony marking the acceptance of the child into the family concern Athens and are late, scanty and contradictory (for example, Suda and Harpocration s.v. Amphidromia; Hamilton (1984); Bonnard (2003); Dasen (1993), (2010b)). It took place in the household on or around the fifth, seventh or tenth day after birth. The baby was carried around the hearth, perhaps physically inspected (Schol. Aristophanes, Lysistrata 757; Plato, Theaetetus 160e-161a). Sacrifice and feasting followed. Those who attended the delivery were then purified. The name-giving ceremony may have taken place the same day or later on the tenth day (dekate) with relatives and friends who witnessed the father's decision and brought birthday gifts.

Within one year of birth, the child was then registered in its father's phratry at the autumn festival of the Apatouria. Other rituals took place, such as going to sanctuaries to thank the gods for a happy delivery. On the Echinos relief, the baby is presented to Artemis, patron of childbirth and a fostering deity, by the mother and servants leading an animal for sacrifice (Figure 18.5) (Morizot (2004)).

\subsection{The Dies Lustricus}

The ceremony of the dies lustricus marked the next decisive step in the child's life and opened a new cycle of passages. The baby received a first social identity: an individual name, a praenomen, which will be completed by the nomen of his gens. The calendar is gendered: the ceremony took place eight days after birth for girls, nine for boys (Plutarch, Roman Questions 288B-E; Macrobius, Saturnalia 1.16.36). 


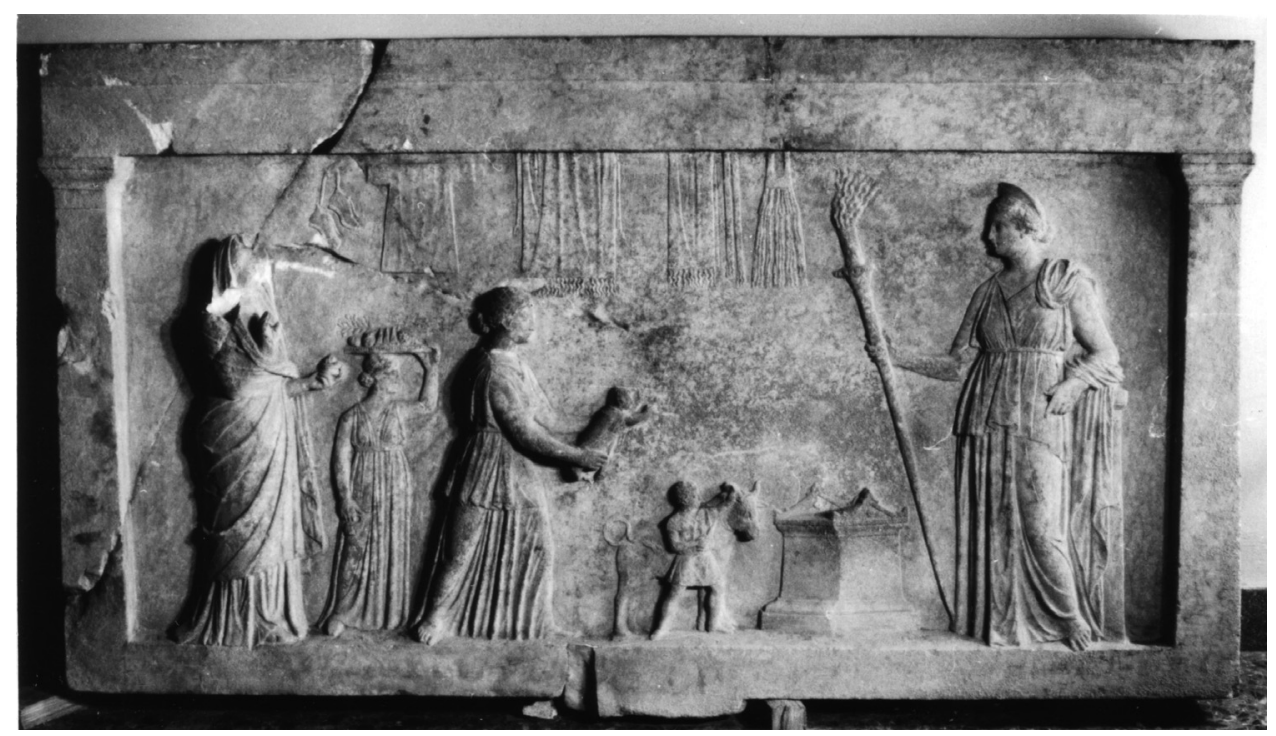

Figure 18.5 Marble votive relief, from Echinos, ca. 300 BCE. Lamia Museum AE 1041; courtesy of Lamia Museum.

In Rome as in ancient Greece, the reason for postponing the naming is partly associated with the high infant mortality (cf. Aristotle, History of Animals 588a8-10). The slow transformation of the child's body through bath, massage, and food played a role too.

Naming practices usually followed family traditions, passing in Rome, for example, from father to sons or daughters. In some regions, they could have other purposes. D.W. Hobson (1989) and O. Masson (1996) demonstrated the protective value of copronyms, derogative names deriving from kopreus, "dung" (Kopreias, Koprias, Kopreas, ... ), found mostly in Roman Egypt, which actually meant to make the newborn look undesirable and repel the threat of the evil eye.

Little is known about the events taking place on the dies lustricus: we read about sacrifices, lustrations and family gathering. Cognati in the female line may have played a special role. Persius describes an apotropaic gesture made by the maternal aunt:

Look - a grandma (avia), or superstitious aunt (matertera), has lifted the boy from his cradle and first protects his forehead and wet lips with her wicked finger and magical saliva, an expert at warding off the withering evil eye. (Satire 2.31-34; Brind'Amour and Brind'Amour (1971))

This gesture is perhaps evoked on a miniature onyx alabastron (50-30 BCE), now in Berlin, where three women hold and touch a baby (Figure 18.6). E. ZwierleinDiehl (1999) argued that they could represent the Carmentes, the divine protectresses of a child belonging to the imperial family, possibly Marcellus (Ovid, Fasti 1.631-36; Macrobius, Saturnalia 1.7.20). One of them holds a jug that could refer to purification rites on the dies lustricus. 


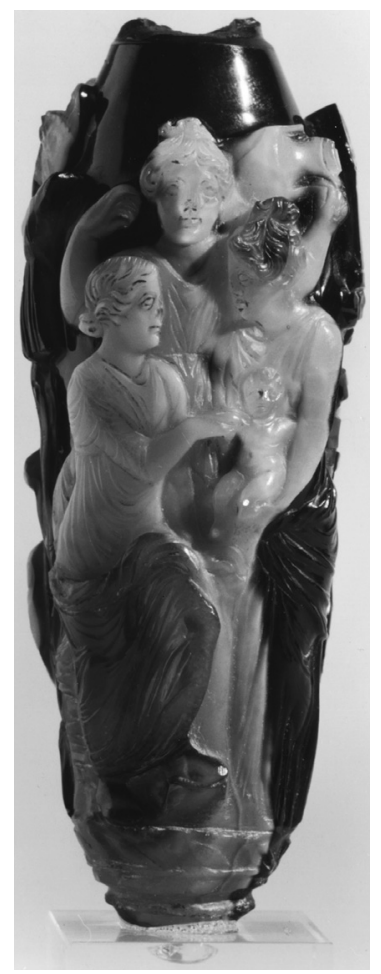

Figure 18.6 Onyx alabastron, ca. 50-30 BCE. Berlin, Antikensammlung, Staatliche Museen FG 11362; (C) and courtesy of Staatliche Museen zu Berlin.

\section{Birth Rites Disrupted by Death}

The Amphidromia and the dies lustricus mark the first step of the child in public life, but do not represent the equivalent of Christian baptism. Children dead before the naming day were not impure and did not transform into malevolent ghosts (BaillsTalbi and Dasen (2008); Dasen (2010c)).

For the last 15 years, an increased attention on burials of infants has favored the discovery of numerous graves of fetuses and newborn babies outside traditional funerary contexts which explains their striking underrepresentation in communal funerary spaces. I develop here the example of Roman Gaul, but similar discoveries are now being recorded in Italy and other Roman provinces (Blaizot et al. (2003); Laubenheimer (2004); Baills-Talbi and Blanchard (2006)). In Greece, the most impressive recent find is that of a cemetery with over 2,500 babies in pots (enchytrismoi) on the island of Astypalaia in the Dodecanese (seventh century BCE to first century CE), still in the course of excavation and study; babies are clearly separated from other dead (Hillson (2009); Michalaki Kollia (2010)).

In Roman Gaul, infants under six months to one year of age can be buried either in settlements, near the living, within houses, along the walls, or outside the house, along the walls, as in a villa rustica in Langeais (France), excavated in 2000 
(Guiot et al. (2003)); 18 newborn babies were discovered, 12 inside the house, six outside along the wall, all at a perinatal age, about one month old. In Pourliat, near Clermont-Ferrand, a space outside the enclosure of a villa rustica revealed 27 babies in pots or plain earth, none older than six months; the youngest is a viable fetus about seven lunar months old (Alfonso and Blaizot (2004)). Infants may also be found beneath the floors of workshops, as in the pottery building of Sallèles d'Aude (Duday et al. (1995)). They remind of the practice mentioned by Fulgentius, Study of Ancient Words (Expositio sermonum antiquorum) 7 in the fifth century CE that children under 40 days old were buried "under the eaves" of the houses. Similar discoveries have also been interpreted as traces of infanticide, human sacrifices, or beliefs in "repeater children" (Scott (1999); Baills-Talbi and Blanchard (2006); Gusi and Muriel (2008)).

Funerary rites confirm the liminal status of newborns which received distinct funerary treatments. Inhumation, in a broken vessel, in plain earth covered with a tile or in a coffin, is common to the whole group of children. Ancient texts allude to it, such as the famous passage of the elder Pliny (Natural History 7.72) explaining that children who have not yet teethed are not cremated. It seems possible to relate the degree of social integration of the child in the community to an increasing diversity of material. In Sallèles d'Aude, twelve graves were arranged along the walls; seven are newborn babies, about ten lunar months, four are children from one to three months, the oldest is between six to nine months old. The newborns were buried with no material; a tile, sometimes fragmentary, marked the grave. Infants up to three months were found in a bigger shaft, covered by a larger tile; one of them had a fibula, perhaps a present attached to the swaddling by the mother. The oldest child had a more elaborate, brick-lined grave covered with two tegulae and a set of objects: a perfume bottle, a lamp, a small cup perhaps with food. This pattern is found in several places. After six months, which corresponds to the teething period and the introduction of solid food, child burials tend to have the same equipment as adults, but with specificities, such as miniature objects, adapted to their size (Gourevitch et al. (2003)).

The absence of funerary offerings with fetuses or newborn babies is not systematic. Some burials show care for the afterlife of the newly born. A grave from a first-century CE cemetery in Aventicum (Switzerland) yielded a newborn baby (ten lunar months) with a funerary coin (Figure 18.7) (Kramar (2005) fig. 5), just born, but safeguarded by mortuary rites, though it may not yet have a name. Another example shows that even babies who were never "born" could receive a fitting burial. A coffin from the fourth-century cemetery in Poundbury (England) contained the remains of a child cut into pieces and extracted by embryotomy, because it was very big and blocked during delivery. The baby was decently buried in a coffin, alone, which suggests that the mother survived (Gourevitch (2004) 262-63).

Burial practices thus indicate that infants had a liminal status allowing them to stay within or near settlements. Their fragility did not imply indifference from the parents. Not yet fully social beings, they did not need to be separated from the domestic space. Their breast-fed bodies did not pollute the house and they were no threat to the living. Ancient authors, such as Cicero or Plutarch, recommend restraint in children's mourning (Cicero, Tusculan Disputations 1.39.93; Plutarch, Numa 12.3). 

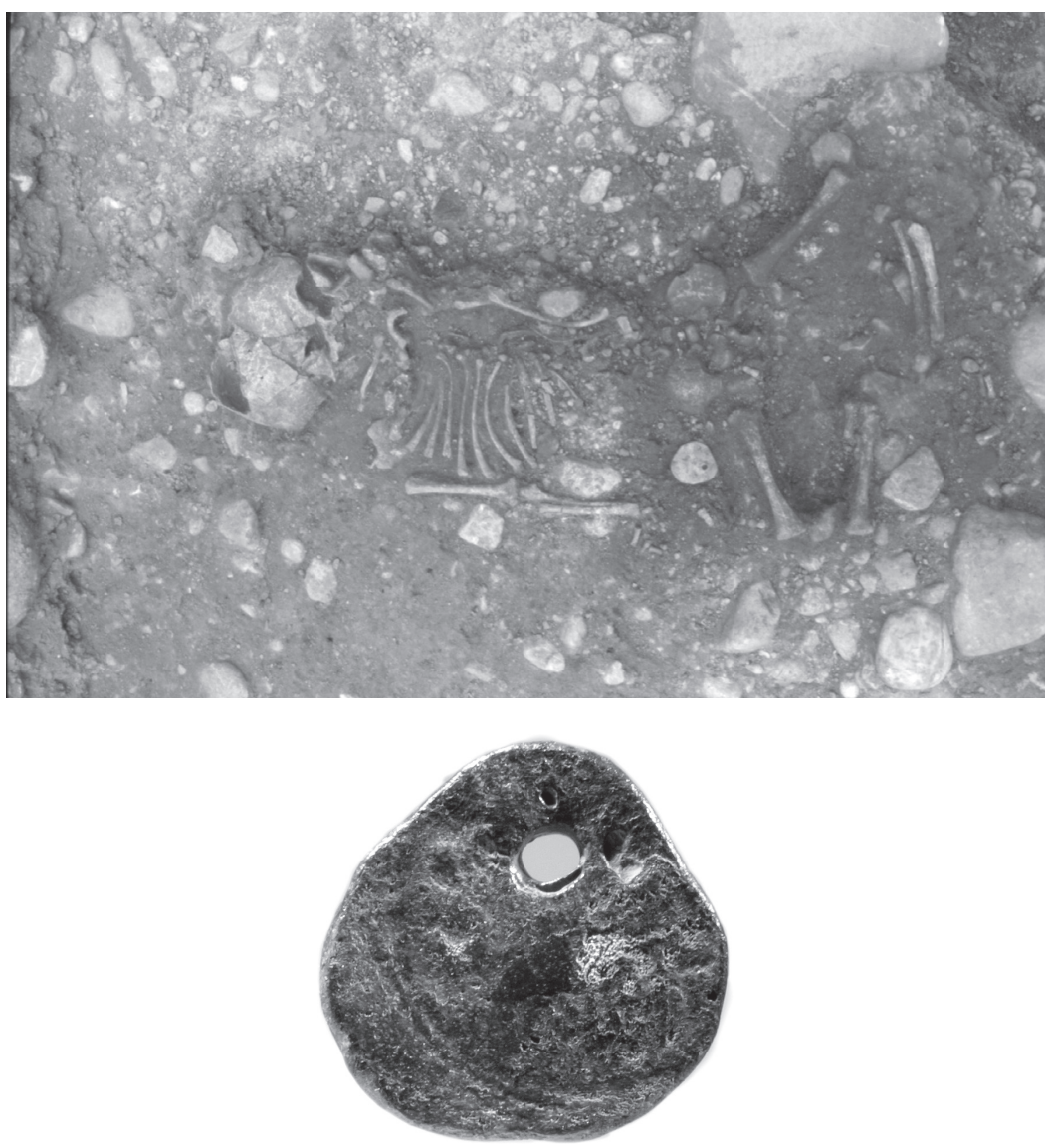

Figure 18.7 Grave, newborn baby (ten lunar months) with a funerary coin, from Aventicum, cemetery A la montagne, St 125, 30-70 CE. Avenches, Musée romain, inventory 01-02/11322-1; (C) and courtesy Avenches, Musée romain.

What could be more discreet than being buried in or near the house, without leaving the domestic space (Dasen (2009b), (2010c))? (On grieving practices, see also Laes, this volume.)

\section{The Growing Child}

\subsection{Wet-Nurses and Other Child-Minders}

Until weaning is completed, the growth of the child depends on the quality of its food. In Greek and Roman culture, parents often entrusted their newborn to a wetnurse (tithene, tithe, trophos/nutrix), usually a slave or a lower-class freeborn woman, who normally lived with them (Figure 18.8). It was advised to choose with care the 


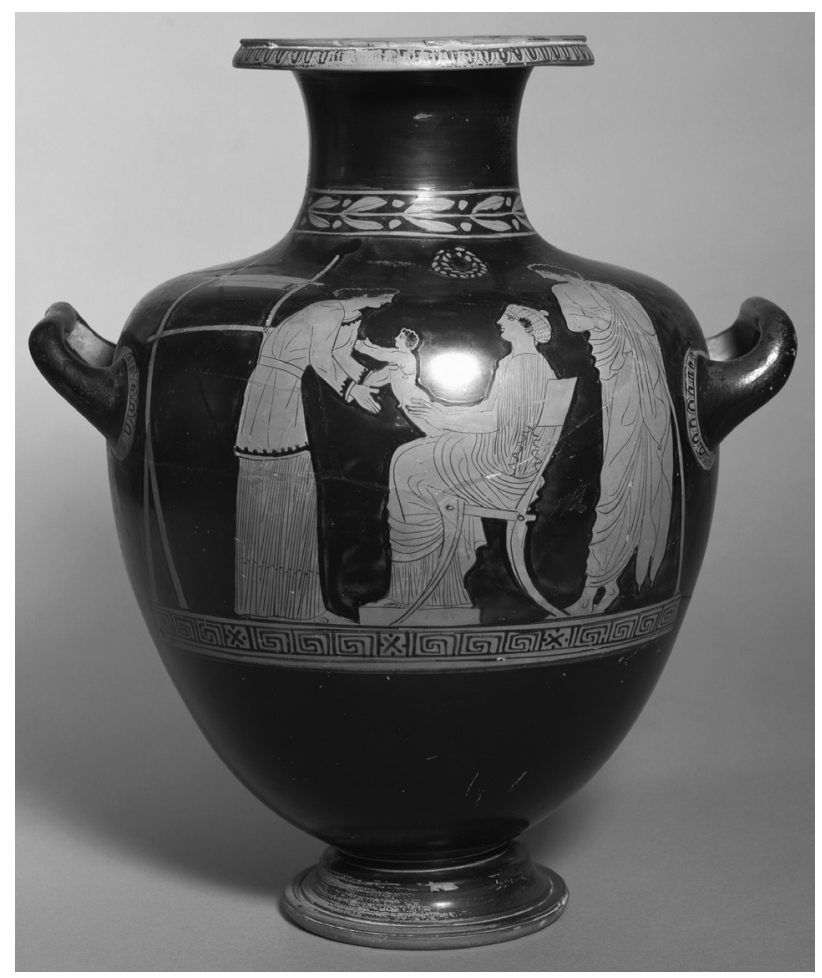

Figure 18.8 Attic red-figure hydria, ca. 440-430 BCE. Harvard Art Museum, Arthur M. Sackler Museum, bequest of David M. Robinson, 1960.342. (C) Michael A. Nedzweski and President and Fellows of Harvard College.

right person, as milk is not a neutral bodily substance, but transmits many properties, physical and moral. Soranus devotes an entire chapter to the meticulous inspection of the nurse's milk ... and temper. The nurse's character must be checked as thoroughly as her physical health. The mind of the newborn, compared with wax (e.g. Tacitus, Dialogue on the Orators 29), is from the start and forever impressed positively or negatively. Mnesitheus (apud Oribasius, Libri incerti 15) and others even advise choosing a woman resembling the mother physically or a handsome person, others (Favorinus apud Aulus Gellius, Attic Nights 12) reject violently the recourse to wetnursing as immoral; submitting the child to the pernicious influence of a foreign nonkin person implies the destruction of family ties (Dasen 2010a). Wet-nurses had to follow a specific diet and to accept giving up their sexual life that would corrupt the milk in case of a new pregnancy (cf. Roman Egypt contracts; Gourevitch (1984) 248-58).

Roman upper-classes families attributed different qualities to nurses according to their ethnic origin: Egyptians were allegedly fond of children, Thracians robust and devoted, Spartans tough. The best ones were the Greeks, because they would teach Greek language - and culture - to their nurslings (Soranus, Gynaecology 2.8[19]; cf. Quintilian, Institutio Oratoria 1.1.3-4; Rühfel (1988); Schulze (1998); Dasen (2010a)). 


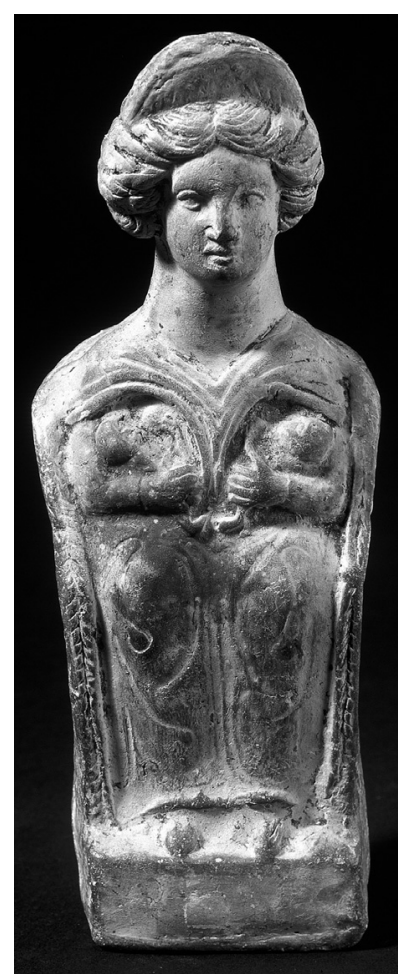

Figure 18.9 Terracotta, second century CE. Musée gallo-romain de Lyon, Département du Rhône, inv. Comarmond 117; ( $)$ and courtesy of Ch. Thioc.

The nurse's social function was extensive. Her role did not stop at the weaning period. Much evidence shows that in Greece as in Rome she was a life-long companion. In positive circumstances, she could construct non-kin relationships and became, through connections not of blood, but milk, a member of an extended family. Funerary inscriptions and literary sources show that some nurses were rewarded by freedom (cf. Gaius, Institutes 1.38-39; lists of nutrices in Bradley (1991) 13-36). Breastfeeding also created milk-ties between the nurslings (syntrophoi, trophimoi, collactanei; cf. Plutarch, Cato 1.20.5-7, on Cato the Elder inciting his wife to feed the home-born slaves) who could gain social elevation thanks to this bonding (for example, Corbier (1999a) 1280-1284).

Did parents purportedly entrust their children to wet-nurses in order to keep an emotional distance as a response to high mortality? The question is debated. The mother was not always physically able to provide milk (Soranus, Gynaecology 2.7[18]), and a well-chosen nurse would provide the best possible food for the child.

In Italy and in the provinces, besides the wet-nurse, upper-class children had an array of child-minders, including men, paedagogus, tata, nutritor, educator, perhaps replacing absent fathers (Golden (1990); list in Bradley (1991) 37-75). Their number and variety reveal the dynamics of ancient families which included kin and 


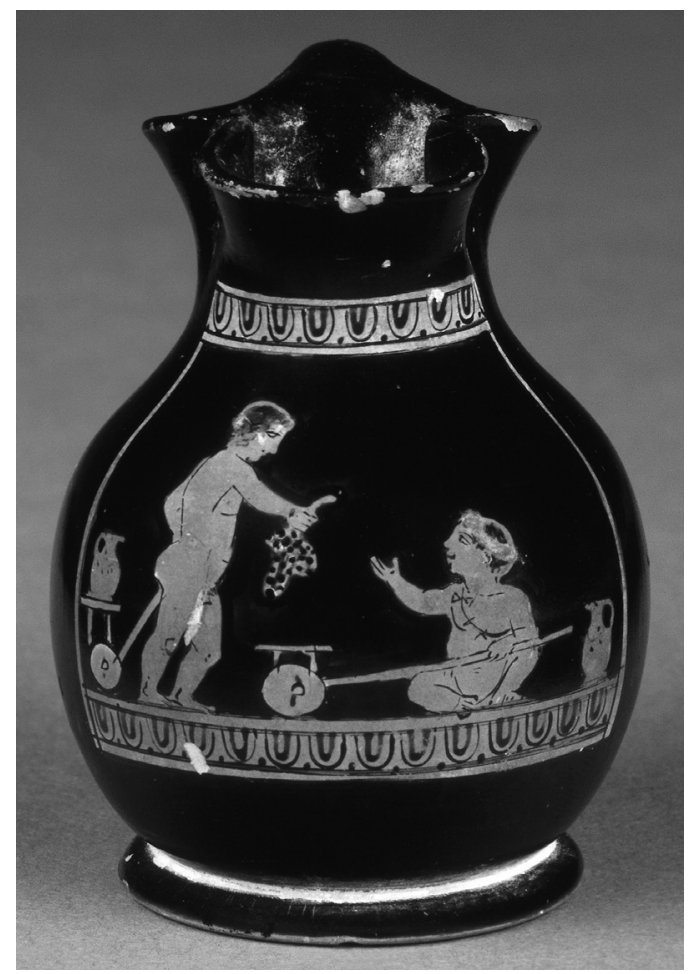

Figure 18.10 Attic red-figure chous, 420-410 BCE. London, The British Museum E 536; (C) and courtesy of the Trustees of the British Museum.

non-kin members who shared responsibility, guilt, and anxieties, and helped "cushion" the loss of the child. The divinization of nursing (kourotrophic) practices witnesses the importance of the task (Figure 18.9) (Dasen (1997)). Did not Demeter herself transform into the nurse of the baby Demophon when she arrived in Eleusis? (Homeric Hymn to Demeter 219-74; Pirenne-Delforge (2010); but cf. Bonfante (1997) on the disquieting connotation of nursing mothers exposing their breasts in classical art).

\subsection{Divine and Magical Protection}

Iconography and archeological objects indicate that children wore various types of amulets to avert diseases and evil influences responsible for untimely deaths (Sorlin (1991); Johnston (1995); McDonough (1997); Dasen (2003a), (2003b)). No text specifies when they were offered. Was it at birth, on the Amphidromia/dies lustricus along with gifts (optêria or genethlia), or on a later occasion? Beside protection, these objects also completed their social and gendered identity.

In Greece, children wore strings of amulets of various shapes (moon-crescent, double-axe, etc.), associated with bracelets and anklets (Figure 18.10), with local variants, 
as on Cypriote statues of so-called temple-boys (Beer 1994). Some amulets have a funerary meaning. The bone cicada of the three-year-old girl from Abdera refers to her status as nymphe, or potential bride, like the pomegranate, the shell and other elements which composed a necklace deposited in her tomb (Kallintzi and Papaikonomou (2006) 483, fig. 4; Papaikonomou (2008) fig. 7).

In Rome, the golden bulla is the most well-known amulet with clear gendered and social connotations. Reserved for boys, it was most likely given by the father himself, as Tarquin the Elder did, according to the legend (Plutarch, Moralia, Roman Questions 287F-288B; Pliny, Natural History 33.10; Palmer (1989)), and hence possibly at the dies lustricus to mark the child's entry into the paternal line. As a token of free birth, the bulla was proudly exhibited by freedmen's children (Huskinson, this volume, Figure 31.6). Bullae are almost never found in a funerary context, perhaps because the amulet was transmitted to another child if the boy died prematurely.

The gendered distribution of the other types of amulets is more difficult to establish. The lunula (selenis, meniskos), a moon-crescent shaped pendant, tended to be given to girls and women, phallus to boys, little bells or antlers' roundels to both. All are part of protection rites, and aimed at promoting a harmonious growth. A geographic distribution can be charted. Lunulae are widely distributed around the Mediterranean, whereas the bulla is typically Italian, bells and antlers Gallo-Roman.

\subsection{First Steps, First Activities}

One of the first toys was probably a rattle, especially adapted to infants, as Aristotle explains:

Besides, children should have something to do, and the rattle of Archytas, which people give to their children in order to amuse them and prevent them from breaking anything in the house, was a capital invention, for a young thing cannot be quiet. (Politics $8.51340 \mathrm{~b} 25-28)$

Apart from toys imitating adult activities (Aristophanes, Clouds 877-81; Plato, Laws 1.643b-d; André et al. (1992)), infants played too with animals; numerous depictions display their intimacy, reflecting their similar nature. The child itself may be called a "cute puppy" (Xenophon, Cyropaedia 1.4.4). Animals also have various symbolical associations (on birds, see Cohen in Cohen and Rutter (2007)), and could also correspond to educational strategies (Bradley (1998b); Coulon (2004) 102-10). In Greece, terracotta models of various animals, especially dogs and cocks, found in tombs could substitute for the real companion, others (for example, sheep, ox) may refer to the sacrifices which should have marked coming of age rituals or remind of those performed in funerary rites (Papaikonomou (2006); Kallintzi and Papaikonomou (2006)).

Dolls are associated with older girls who passed the weaning period and acquire a sexual identity. Greek dolls are not proper toys, but correspond to maturation 
rites (Reilly (1997); Dasen (2005c), (2010c)). One was found in the tomb of a two/three-year-old girl from Abdera, at the weaning age (Papaikonomou (2006), (2008) fig. 6). Another doll was found in Ampurias with a girl of unknown age but also with a feeding bottle, alluding to the same age class (Papaikonomou (2008) figs 9-10).

Among the first accomplishments, learning to walk is evoked in Greek iconography (Figure 18.10). More elaborate walkers are depicted in Roman art, as on a famous life-cycle sarcophagus in Rome (Rawson (2003) fig. 3.1).

\section{End of Infancy}

Around three years of age, the status of the infant changed. Material traces of the weaning period may be seen in feeding bottles found in tombs, though their real function is not easy to determine. Some had a funerary purpose, like vessels in the shape of a pomegranate (Neils and Oakley (2003) No. 33) or Roman glass bottles, too frail for daily use (Rouquet (2003)), others could contain other liquids (Soranus, Gynaecology 2.17[46]; Gourevitch and Chamay (1992)), particular shapes were used as breast pumps (Rouquet (2003)).

Rituals marked the end of infancy. In Classical Athens, three-year-old children, boys and girls, joined in the Dionysiac festival of the Anthesteria, held in spring. On the second day, Choes, a drinking contest marked their first active participation to a public ceremony. Children seem to have received as gifts miniature wine jugs with depictions of babies and children's activities which do not all relate to the festival (cf. Figure 18.10; Hamilton (1992); Ham (1999); Neils and Oakley (2003) 145-49; Dasen (2005c); Smith (2007)). Votive reliefs also show young children taking part in processions with their family (Lawton (2007)).

No feast similar to the Anthesteria was conducted in the Roman world, but other rituals may be identified. In the sanctuary of the Leni in Trevi, fathers dedicated to Mars Iovantucarus, "who is fond of youth," inscriptions and statues of toddlers for the salus of their sons and daughters (Derks (2006)).

\section{Conclusion}

Birth and infancy were an extensive process in classical antiquity. Many steps constructed the human identity of the child who was for a long time not considered entirely formed, physically, emotionally and mentally. High mortality, however, did not prevent bonding, even in societies which allowed newborns' exposure (Golden (1990) 86-88). Myths of baby heroes transcend children's deaths (Pache (2004)). Their physical and intellectual differences could be viewed negatively but were also enjoyed. Plentiful evidence evokes their irresistible qualities, such as their soft and sweet smelling skin (Euripides, Medea 1071-75, 1402-403), charming smile (Herodotus 5.92), attitudes (Plutarch, Consolation to His Wife 608D, McNiven (2007); Dasen (2008b)) and babbling (Golden (1995)). Children's iconography 


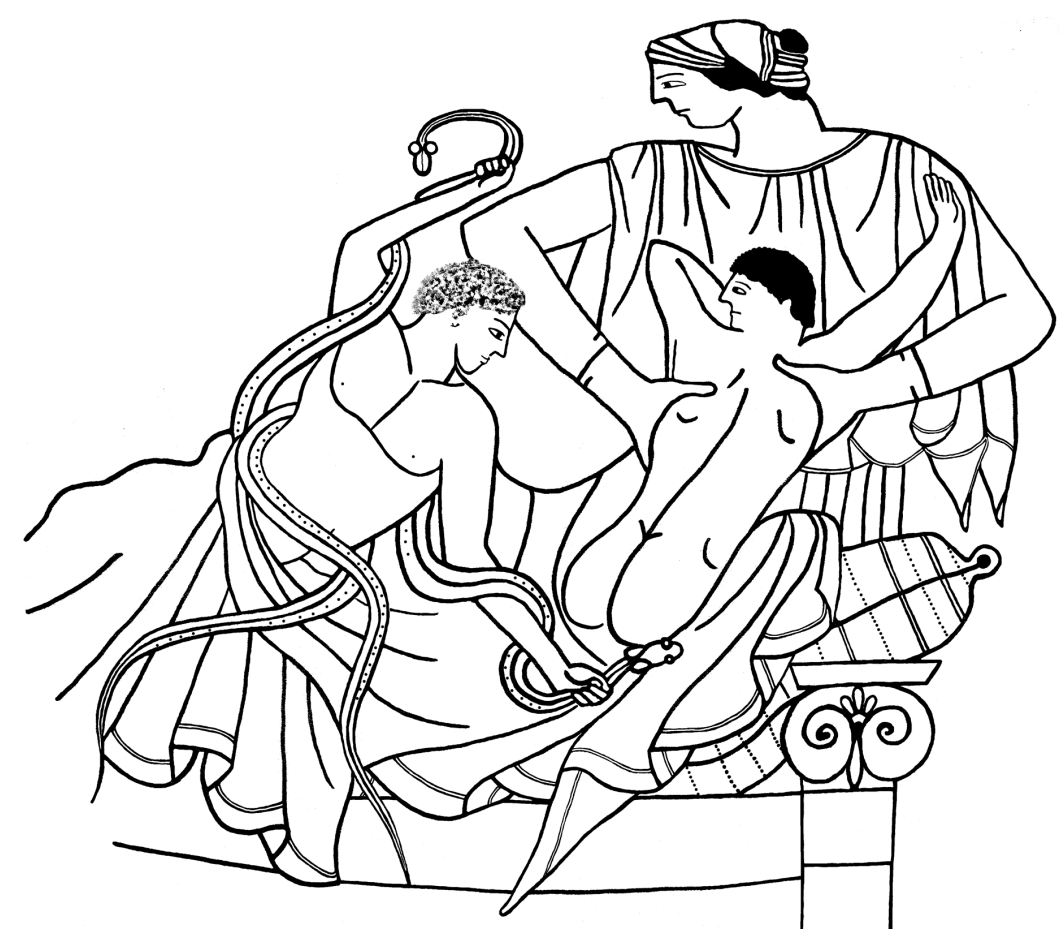

Figure 18.11a Stamnos, Berlin Painter, ca. 480 BCE. Paris, Louvre G 192; drawing by Véronique Dasen.

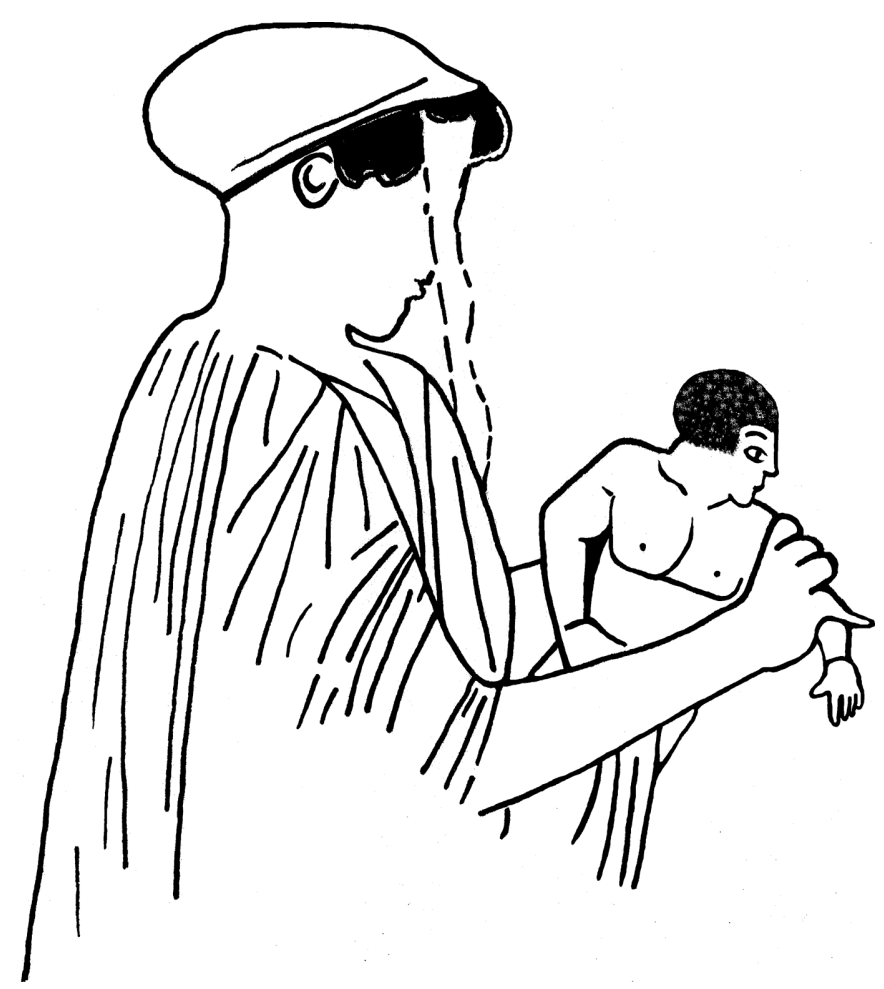

Figure 18.11b Lekythos, manner of the Pistoxenos Painter, ca. 470 BCE. Oxford, Ashmolean Museum V 320; drawing by Véronique Dasen. 
reflects ancient views of infantile bodies. The model of baby Heracles, which appears around $480 \mathrm{BCE}$, depicts an athletic child, born to survive (Figure 18.11a); its influence on scenes of daily life may be seen on vase paintings where baby boys look like miniature body-builders with developed pectorals. On the Oxford lekythos (Figure 18.1 lb) the baby's attitude stresses his vigor. His attention is attracted to the right, and his mother must strongly hold his arm. An inscription above his head stresses the hopes of his parents: "Glaukos, son of Leagros, is beautiful," projecting the baby into the future as a kalos, attractive young boy.

\section{FURTHER READING}

Childbirth and infancy are new topics within the broader field of the history of childhood. Golden (1990) and Garland (1990) for Greece, Rawson (2003) for Rome provide excellent historical overviews, mainly based on textual and epigraphical evidence. The rediscovery was promoted by the study of medical writers, especially Soranus of Ephesus, who details childbirth and the first hours of life. Gourevitch edited and translated into French his treatise (Burguière et al. (1986)) and dedicated many articles to issues addressed by this author ((1989), (1994), (1995), (2004); Gourevitch et al. (2003)). A synthesis is still missing on ancient pediatrics and puericulture. Most studies focus on authors of the Roman imperial period (Bertier (1996); Holman (1997); Hummel (1999); Hanson (2003); Mudry (2004); Bradley (2005)). The literary evidence on Roman birth rites of passage is revisited by Köves-Zulauf (1990); Shaw (2001); and Dasen (2009b). These rites are less known in Greece (Hamilton (1984); Bonnard (2003)), but festivals, such as the Anthestheria, are better documented (Hamilton (1992); Ham (1999); Dasen (2005c), (2010b)).

Archeology (including paleopathology) is a major source of information. The pioneering work of Coulon (2004) provides a wealth of material from Gallo-Roman society, as well as the exhibition catalogs on ancient Greece edited by Neils and Oakley (2003) and on Roman Gaul (Gourevitch et al. (2003)). These are completed by articles on particular categories of artifacts, such as amulets (Palmer (1989); Dasen (2003a), (2003b)), feeders (Rouquet (2003)), and skeletal remains (Gourevitch (2004)). André et al. (1992) offer an overview of toys, but their identification is debated. Greek dolls are no more interpreted as toys (Reilly (1997); Dasen (2005c); Papaikonomou (2008)), nor figurines of animals found in funerary contexts (Papaikonomou (2008)).

Scott (1999) provides a first approach to burial practices. No synthesis is yet available, but many monographs and articles present case studies (Duday et al. (1995); Blaizot et al. (2003); Laubenheimer (2004); Gusi et al. (2008)). Comparative approaches to infancy are still few, though those that do exist offer useful transfers of questioning, as in the collection of papers edited by Dasen (2004) and Cohen and Rutter (2007). 